\section{Carbon Colloids Prepared by Hydrothermal Carbonization Power Indirect Carbon Fuel Cells}

Electrochemical conversion of carbon to electrical energy has its origins in the late 19th century. A carbon fuel cell is conceptually much more efficient than combustion for converting the chemical energy in coal into electrical energy. Because the activation energy for the electrochemical oxidation of carbon is high, direct carbon fuel cells (DCFCs) require high temperatures (between $500^{\circ} \mathrm{C}$ and $1000^{\circ} \mathrm{C}$ ), which limits their application. Alternatively, indirect carbon fuel cells (ICFCs) employ a secondary oxidant to oxidize carbon. The secondary oxidant is renewable, that is, it is reoxidized at the anode. ICFCs can therefore operate at temperatures in the range of about $80-100^{\circ} \mathrm{C}$, although the theoretical decrease in cell voltage is about $50 \%$ from about $1 \mathrm{~V}$ (for DCFCs) to $0.5 \mathrm{~V}$. ed for an ICFC with a $\mathrm{Fe}^{3+} / \mathrm{Fe}^{2+}$ secondary redox system in the anodic half-cell using a Promising results were previously report-

fuel of subbituminous fossil coal. Recently, J.P. Paraknowitsch, A. Thomas, and M. Antonietti of Max-Planck-Institute of Colloids and Interfaces, Potsdam-Golm, Germany, have shown that the efficiency of ICFCs can be increased even further with a fuel of carbon colloids.

As reported online on March 3 in Chemistry of Materials (DOI: 10.1021/ $\mathrm{cm} 801586 \mathrm{c})$, the research team obtained water-dispersible carbon colloids from a process called hydrothermal carbonization (HTC), which dates back to early 20thcentury studies of coal formation from carbohydrates. Specifically, D-glucose, which the researchers regard as a model compound for several biomass sources, was heated in water in a closed reaction vessel for 4-24 h at a temperature of about $200^{\circ} \mathrm{C}$ to form HTC coal. In addition to the expected zero balance for $\mathrm{CO}_{2}$, the researchers said that another advantage of HTC coal is the hydrophilic surface structure; Fourier transform infrared spectra show bands of hydroxylic and carbonylic groups. Other advantages include the

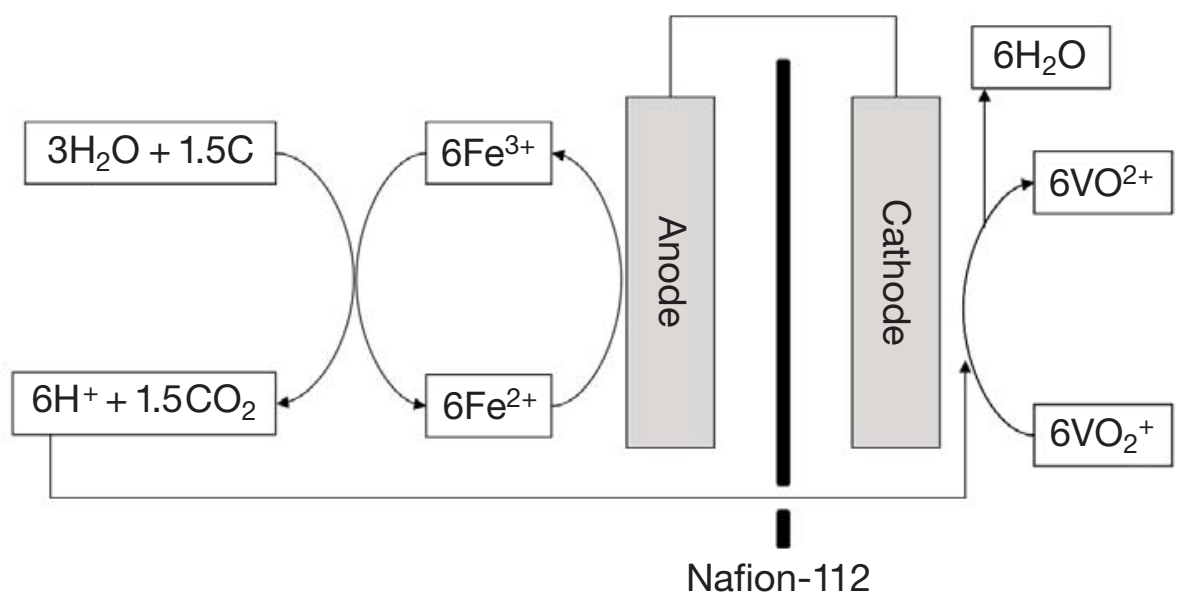

Figure 1. Schematic representation of the secondary redox concept for an indirect carbon fuel cell. micrometer spherical particles and the HTC coal's amorphous structure, which are ideal for a water-based fueling system. Furthermore, the low contents of sulfur and ash in HTC coal from biomass will serve to minimize interactions with the secondary redox system.

The researchers used an ICFC similar to the one previously proposed but replaced the cathodic oxygen half-cell with a $\mathrm{VO}^{2+} / \mathrm{VO}^{2+}$ cathodic half-cell in order to make the fuel cell more suitable to a laboratory scale (see Figure 1). Reference measurements made with a half-cell containing only an $\mathrm{Fe}^{3+}$ solution showed negligible current, as expected. However, when the reference solution was replaced with a mixture of $50 \mathrm{ml} \mathrm{Fe}{ }^{3+}$ solution and 1 gram of HTC coal that had been stirred (in order to disperse the HTC carbon particles) at $100^{\circ} \mathrm{C}$ for $1 \mathrm{~h}$, the measured current increased markedly, leveling off at about 2-2.5 mA after about an hour. The researchers said that formation of $\mathrm{Fe}^{2+}$ ions from oxidation of the carbon source leads to an increase of both open-circuit potential and, when both half-cells are short circuited, electric current. The researchers found very similar results when lignite was used as a carbon source. However, anthracite performed poorly, attaining a current of less than $1 \mathrm{~mA}$.

These ICFC results are consistent with the oxidation rates previously obtained by the researchers from a standard oxidation assay. An efficiency of about $4 \%$ was achieved for HTC coal and for lignite in a salt bridge-based ICFC, which improves to about $14 \%$ for a Nafion membranebased ICFC, which the researchers attribute to better charge equilibration in the latter ICFC. The researchers said that "using carbon colloids derived from hydrothermally treated biomass would indeed yield an indirect carbon fuel cell with an overall zero-emission balance concerning the green house gas $\mathrm{CO}_{2}$."

STEVEN TROHALAKI

\section{Nanostructured Device Design Based on Plasmonic Crystal Confinement May Enable Single- Molecule Detection}

The ability to detect single molecules in a rapid and reliable fashion would bring enormous benefits in many areas, from homeland security to medical research to early disease detection. Many researchers pursuing this goal have focused on optical techniques, which can operate extremely quickly and potentially from a distance. However, obtaining a detectable interaction from a single molecule at rele- vant optical wavelengths requires light to be compressed many times smaller than the diffraction limit, a challenge that has hindered progress in this area. Now, R.M. Gelfand, L. Bruderer, and H. Mohseni at Northwestern University have demonstrated the design of a nanostructured device that may represent a solution, which they report in the April 1 issue of Optics Letters (DOI: 10.1364/ OL.34.001087; p. 1087).

The basic concept of optical singlemolecule detection is to observe the spectral absorption fingerprint of target mole- cules. To be practical, the interaction between the light and the molecule must be made much stronger than in free space, which generally requires confinement of the light and molecule in some structure that enhances the optical intensity and increases the interaction time. Unfortunately, standard cavity structures generally have too small a spectral bandwidth to allow detection of the molecular spectral fingerprint, and are also overly sensitive to small manufacturing or environmental variations.

The Northwestern team addressed this 
problem by designing a device that combines a metal-dielectric-metal (MDM) sandwich structure with a plasmonic crystal. The MDM structure, made from 200-nm-thick metal outer layers and a 12-nm-thick dielectric inner layer, provides planar plasmonic light confinement. It is pierced with a two-dimensional hexagonal array of 450-nm-diameter holes spaced at $500 \mathrm{~nm}$ intervals, providing lateral plasmonic crystal light confinement. The structure also contains a detection region that consists of a single defect in the crystal with a volume of only 15 zepto- liters (40 nm diameter, $12 \mathrm{~nm}$ thick). Using finite-difference time-domain simulations, the team showed that the extremely small detection volume leads to a high Purcell factor (measuring the optical-molecular interaction strength) of $4.8 \times 10^{6}$, more than an order of magnitude higher than the best photonic crystals reported to date. However, the structure also displays a wide spectral bandwidth of $7.4 \mathrm{THz}$ centered around $3.45 \mu \mathrm{m}$, the wavelength region of interest for many molecular vibrational states, enabling robust molecular spectral fingerprinting. Finally, the sim- ulations showed that it should be relatively easy to couple light into and out of the device from a direction orthogonal to the MDM plane, while simultaneously flowing gas or liquid through the defect. The team said that the device's behavior would be relatively insensitive to manufacturing errors within typical tolerances, as well as some environmental effects. Given these results, devices based on a metal-dielectricmetal/plasmonic crystal structure may someday form the basis for practical optical single-molecule detection systems.

COLIN MCCORMICK

\section{Ionic Conduction of Tetravalent $\mathrm{Ti}$ lon Observed in NASICON-Type Crystals Modified by Introduction of High-Valence Elements}

High ionic conductivity in solid electrolytes has been demonstrated, up to recently, for mono-, di-, and trivalent conducting species. Tetravalent cations have been considered extremely poor migrating species in solids because of their strong electrostatic interaction with surrounding anions. However, this strong interaction can be weakened by the introduction in the structure of cations with higher valences, since they will attract the anionic species more strongly than the tetravalent cation, enabling its migration in the solid lattice. N. Nunotani, S. Tamura, and N. Imanaka from Osaka University, Japan, have demonstrated, by applying this strategy, high ionic conduction of $\mathrm{Ti}^{4+}$ in NASICON-type $\mathrm{TiNb}\left(\mathrm{PO}_{4}\right)_{3}$, and $\mathrm{Ti}\left(\mathrm{Nb}_{1-x} \mathrm{~W}_{x}\right)_{5 /(5+x)}\left(\mathrm{PO}_{4}\right)_{3}$ structures. NASICON $\left(\mathrm{Na}^{+}\right.$super-ionic conductor) materials have three-dimensional networks that provide pathways for ionic migration.

As reported in the February 24 issue of Chemistry of Materials (DOI: 10.1021/ cm803193k; p. 579), the researchers observed that, for crystals with $\mathrm{W}$ content at $x=0.2$, the electrical conductivity of $\mathrm{Ti}\left(\mathrm{Nb}_{1-x} \mathrm{~W}_{x}\right)_{5 /(5+x)}\left(\mathrm{PO}_{4}\right)_{3}$ solids at $800^{\circ} \mathrm{C}$ increased substantially yielding a maximum value of conductivity of $3.65 \times 10^{-4} \mathrm{~S} \mathrm{~cm}^{-1}$. For higher values of $x$, the researchers obtained a mixture of $\mathrm{TiP}_{2} \mathrm{O}_{7}$ and $\mathrm{WO}_{3}$. Because the electronegativity of $\mathrm{Ti}^{4+}$ is higher than those of $\mathrm{Zr}^{4+}$ and $\mathrm{Hf}^{4+}$, the ionic conductivity that the researchers measured in $\mathrm{TiNb}\left(\mathrm{PO}_{4}\right)_{3}$ was lower than that measured previously in $\mathrm{ZrNb}\left(\mathrm{PO}_{4}\right)_{3}$ and $\mathrm{HfNb}\left(\mathrm{PO}_{4}\right)_{3}$. However, in $\mathrm{Ti}\left(\mathrm{Nb}_{0.8} \mathrm{~W}_{0.2}\right)_{5.0 / 5.2}\left(\mathrm{PO}_{4}\right)_{3}$, the researchers said that the electrostatic interaction between $\mathrm{Ti}^{4+}$ and $\mathrm{O}^{2-}$ was reduced by the introduction of $\mathrm{W}^{6+}$, and as a result, $\mathrm{Ti}\left(\mathrm{Nb}_{0.8} \mathrm{~W}_{0.2}\right)_{5.0 / 5.2}\left(\mathrm{PO}_{4}\right)_{3}$ exhibited 2.2 times higher $\mathrm{Ti}^{4+}$ conductivity than $\mathrm{TiNb}\left(\mathrm{PO}_{4}\right)_{3}$.
To identify the conducting species in these solids, the researchers investigated the dependence of the ac conductivity with oxygen partial pressure at $800^{\circ} \mathrm{C}$. They observed that above $1 \times 10^{-11} \mathrm{~Pa}$ the ac conductivities were constant. However, below this pressure the ac conductivity increased significantly because of the appearance of electronic conduction caused by the reduction of $\mathrm{Ti}^{4+}$. The researchers also investigated the polarization behavior of this conductivity by measuring the dependence of the dc to ac conductivity ratio with time in oxygen and $\mathrm{CO}-\mathrm{CO}_{2}$ gas mixture atmospheres. This proved that $\mathrm{O}^{2-}$ ions did not migrate in the sample. Furthermore, the researchers directly demonstrated $\mathrm{Ti}^{4+}$ ion conduction in the $\operatorname{Ti}\left(\mathrm{Nb}_{0.8} \mathrm{~W}_{0.2}\right)_{5.0 / 5.2}\left(\mathrm{PO}_{4}\right)_{3}$ solid by performing dc electrolysis at dc voltages higher than the decomposition voltage of this compound, that was established at $1.2 \mathrm{~V}$. In this way, the researchers forced the conducting cation species only to migrate toward the cathode according to the potential gradient. After dc electrolysis, the researchers performed electron probe microanalysis line analysis of the electrolyzed pellet. They observed a clear segregation of Ti only near the cathodic surface, clearly demonstrating the ionic conduction of tetravalent Ti ion.

JOAN J. CARVAJAL

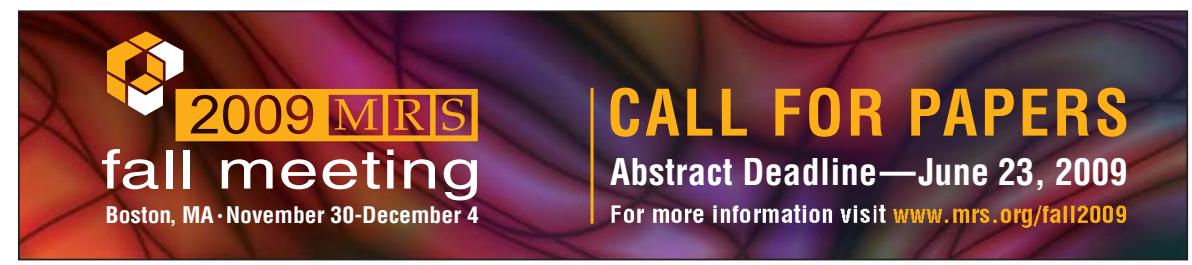

\section{Advertisers in This Issue}

Page No.

Bruker AXS, Inc.

High Voltage Engineering

HORIBA Jobin Yvon

Janis Research Company, Inc.

Lake Shore Cryotronics, Inc.

National Electrostatics Corporation

Otto Schott Research Award

Veeco Instruments, Inc.

For free information about the products and services offered in this issue check http://www.mrs.org/bulletin_ads. 